\title{
CORRECTION
}

\section{Correction to: Prevention of Type 2 Diabetes with the Chinese Herbal Medicine Tianqi Capsule: A Systematic Review and Meta-Analysis}

Bing Pang $\cdot$ Ying Zhang $\cdot$ Jing Liu $\cdot$ Li-sha He $\cdot$ Yu-jiao Zheng $\cdot$

Feng-mei Lian $\cdot$ Xiao-lin Tong

Published online: November 3, 2017

(c) The Author(s) 2017. This article is an open access publication

Correction to: Diabetes Ther

https://doi.org/10.1007/

s13300-017-0316-x

Incorrect author affiliation and the typo in acknowledgement section were found in the original publication.

The correct author affiliations and acknowledgments are given here:

The online version of the original article can be found under https://doi.org/10.1007/s13300-017-0316-x.

B. Pang · L. He · Y. Zheng · F. Lian $(\bowtie)$.

X. Tong $(\bowtie)$

Department of Endocrinology, Guang' anmen

Hospital of China Academy of Chinese Medical

Sciences, Beijing, China

e-mail: lfm565@sohu.com

\section{Tong}

e-mail: xiaolintong66@sina.com

Y. Zhang

Centre for Evidence-Based Chinese Medicine, Beijing University of Chinese Medicine, Beijing, China

J. Liu

Sinobioway Group Co., Ltd., Beijing, China

J. Liu

Weiming Tianren Pharmarceutical co., Ltd., Beijing,

China

J. Liu

Pharmaceutical Co., Ltd., Beijing, China
Ying Zhang's affiliation currently reads: Centre for Evidence-Based Chinese Medicine, Beijing University of Traditional Chinese Medicine, Beijing, China

This should read: Centre for Evidence-Based Chinese Medicine, Beijing University of Chinese Medicine, Beijing, China

Jing Liu's affiliation currently reads: Sinobioway Group Co., Ltd, Pharmaceutical Co., Ltd., Beijing, China.

This text should be separated into 3 separate affiliations and should read:

J. Liu

Sinobioway Group Co., Ltd., Beijing, China

J. Liu

Weiming Tianren Pharmarceutical co., Ltd., Beijing, China

J. Liu

Pharmaceutical Co., Ltd., Beijing, China

In the acknowledgments section on the fifth line, the author name Ting Zhang should read Ying Zhang. The word manuscriipt should also read as 'manuscript'. In the 7 th line, the heading currently reads: Date collection and this should read as 'Data Collection'. 
Open Access. This article is distributed under the terms of the Creative Commons Attribution-NonCommercial 4.0 International License (http://creativecommons.org/licenses/ by-nc/4.0/), which permits any noncommercial use, distribution, and reproduction in any medium, provided you give appropriate credit to the original author(s) and the source, provide a link to the Creative Commons license, and indicate if changes were made. 